\title{
El papel de la cultura popular en la construcción de la identidad nacional mexicana: los fandangos jarochos
}

\author{
O papel da cultura popular na construção da identidade nacional \\ mexicana: os fandangos jarochos
}

\section{The role of popular culture in the construction of Mexican national identity: the fandangos jarochos}

Melba Alí Velázquez Mabarak Sonderegger ${ }^{1}$

\begin{abstract}
Resumen
La convergencia global causada por el uso masivo de los medios y tecnologías de comunicación, así como la replicación del sistema capitalista en las economías mundiales, amenazó con homogenizar culturalmente las prácticas humanas. Sin embargo, la globalización se concretó con antítesis locales: la reafirmación de las identidades nacionales, así como el intento de reivindicar particularismos culturales a través de iniciativas y políticas de reconocimiento a la diversidad cultural. En estas páginas se analiza el papel de la revitalización de la cultura popular en la construcción de la identidad nacional mexicana; en específico, el caso de los fandangos jarochos en su transición de lo rural a lo urbano y los fandangos fronterizos en el marco de la globalización.
\end{abstract}

Palabras clave: culturas populares, fandangos jarochos, identidad nacional, globalización, revitalización de la cultura.

\section{Resumo}

A convergência global causada pelo uso massivo dos meios e tecnologias da comunicação, tal como a réplica do sistema capitalista nas economias mundiais, ameaçou com a homogeneização cultural das práticas humanas. Porém, a globalização concretizou-se com antíteses locais: a reafirmação das identidades nacionais, assim como a intenção de reivindicar particularismos culturais através de iniciativas e políticas de reconhecimento à diversidade cultural. Nestas páginas é analisado o papel da revitalização da cultura popular na construção da identidade nacional mexicana; especificamente, o caso dos fandangos jarochos na sua transição do rural ao urbano, e os fandangos fronteiriços no marco da globalização.

Palavras chave: culturas populares, fandangos jarochos, identidade nacional, globalização, revitalização da cultura.

\section{Abstract}

Global confluence brought upon by massive media and communication technologies, as well as the replication of capitalism by the world economies, has posed the threat of cultural homogenization of human practices. However, globalization resolved itself in local antithesis: the reaffirmation of national identities and the

\footnotetext{
1 (Maestranda en el programa Interdisciplinar em Estudos Latino-Americanos; Universidade Federal da Integração Latino-Americana - UNILA; Foz do Iguaçu, Paraná, Brasil; melba sonderegger@hotmail.com). Trabajo presentado en el I Seminário Latino-Americano de Estudos em Cultura - SEMLACult, Foz do Iguaçu/PR, Brasil, 2017.
} 
vindication of cultural specificities through cultural diversity acknowledgement initiatives and policies. This work analyzes the role played by the revitalization of popular culture on the construction of a Mexican national identity, with a focus on fandangos jarochos and its transition from rural to urban environments, and the case of transfrontier fandangos in the context of globalization.

Key words: popular culture, fandangos jarochos, national identity, globalization, revitalization of popular culture.

\section{La reconstrucción nacional}

En el México postrevolucionario resultó evidente la necesidad de realizar tareas para la reconstrucción nacional después de una década de conflictos armados. La dictadura porfirista de más de treinta años daba paso a un proyecto de Estado-nación pretendidamente democrático y que habría de cumplir las exigencias de la Revolución, con reformas sociales y agrarias y proyectos centrados en las clases populares. Los escombros del país tras la lucha civil eran entendidos como un mosaico conformado por piezas disímiles: múltiples poderes regionales, distintas lenguas indígenas en convivencia con la lengua española, desigualdad económica y social, acceso a la educación relegado a una mínima fracción de la población, diversas prácticas culturales y religiosas, etcétera; un rompecabezas que sólo podría ser gobernado a partir de su unificación.

La integración de esta sociedad heterogénea fue pensada a partir de la comunión de sangres y estirpes. Así, el arquetipo de lo mexicano fue protagonizado por el mestizaje racial, pero sobre todo cultural. Intelectuales como Andrés Molina Enriquez (1961) y José Vasconcelos (1948) consideraron al mestizo como la quintaescencia del progreso, el motor de la historia. Vasconcelos imaginó una patria mestiza que eliminaría de origen los conflictos causados por las diferencias sociales, dado que estaría integrada uniformemente por individuos dotados de cualidades dominantes y lo mejor de las culturas, sin desigualdades arbitrarias. De ahí el lema que eternizó para la Universidad Nacional cuando fungió como su rector: "Por mi raza hablará el espíritu". El intelectual incluso apunta a una unificación más allá de las fronteras nacionales (a las que considera infructuosas en Iberoamérica) para alcanzar el estado del hombre mejorado por el mestizaje, profundamente universal.

El Estado-nación ${ }^{2}$, desde sus instituciones, se representó como una totalidad simultáneamente plural y común a todos los individuos, y en el valor simbólico de su

\footnotetext{
${ }^{2}$ A diferencia de los Estados multinacionales, que contemplan relativa soberanía de los pueblos (naciones) que le integran, el Estado-nación se contempla como una administración centralizada de diversos pueblos
} 
cohesión radicó su poder político. El constructo mental de los mexicanos sobre la mexicanidad reposó sobre las espaldas de múltiples elementos culturales de distintas épocas de su historia, a fin de generar una narrativa unificada del territorio y arraigar las semillas del nacionalismo. Benedict Anderson (1993) describe el nacionalismo como un artefacto cultural cuya legitimidad es emocional y responde a la necesidad de establecer una comunidad política pensada como limitada y soberana. Dado que las naciones se constituyen por una comunidad imaginada -sus integrantes no serán capaces de conocer el total de la población que la conforma, pero la imaginan como una masa vasta y finita-, es preciso reforzar los lazos que mantienen la cohesión social y legitiman políticamente al Estado.

Las comunidades imaginadas pueden estar cimentadas por bases religiosas, como lo fue durante varios siglos la Nueva España. La religión católica fungió como un vínculo social en la población desde la Conquista española, con el adoctrinamiento masivo de indígenas y su consecuente práctica por criollos y mestizos (MOLINA, 2012). Sin embargo, los recursos de unificación del México posrevolucionario -que, recordemos, se autodenominaba soberano y democrático- no podían descansar exclusivamente en las instituciones eclesiásticas, pues el país ya se pretendía laico desde un siglo antes, con las Leyes de Reforma. A pesar de que emblemas religiosos como la Virgen de Guadalupe eran reconocidos y aceptados por la mayoría de los mexicanos, las instituciones del Estado tuvieron que recurrir a otros símbolos seculares. En el ocaso del poder religioso el nacionalismo surge como oposición en el plano de lo trascendental (ANDERSON, 1993). Como sustitución seglar a las figuras de los mártires -tan eficaces en el catolicismo- pueden enunciarse los mitos de los héroes nacionales. Verbigracia, la imagen de Juan Escutia, el niño héroe, envuelto en la bandera mexicana, sacrificando su vida por el honor de la patria en la Batalla de Chapultepec contra las tropas estadounidenses.

Héroes y símbolos patrios no son los únicos emblemas del nacionalismo, éste también puede recaer en otros artefactos culturales; la literatura, por ejemplo. Anderson (1993) advierte la gran repercusión del capitalismo impreso en los orígenes de la conciencia nacional, al fijar lenguas vernáculas como instrumentos de centralización administrativa, por lo menos la Europa del siglo VI. Sin embargo, en la América hispana, los fundadores criollos que

(independientemente de su lengua o cultura) a través de instituciones sociales, económicas y políticas compartidas (VIZCAÍNO, 2006). 
pugnaban por la independencia del imperio no postularon las lenguas autóctonas como lenguas nacionales, sino que adoptaron el idioma colonial (su propio idioma) como el lenguaje del poder. Un siglo después, la producción editorial en el México posrevolucionario transmitía en lengua castellana "una voluntad de poder nacionalista ligada a la unificación e institucionalización del Estado capitalista moderno" (BARTRA, 1987: 17). Los intelectuales dilucidaban sobre "lo mexicano" desde diversas ramas de conocimiento para descifrar el carácter de su identidad, ya sea descubriéndolo, rescatándolo o inventándolo (VIZCAÍNO, 2004).

Pero poco de estos esfuerzos por definir la identidad nacional podían llegar al grueso de la población, compuesta por campesinos, indígenas y obreros, de mayoría analfabeta. Apenas uno de cada seis mexicanos conseguía leer y escribir (LIRA, 2014). A pesar de la intensa cruzada por la educación que Vasconcelos inició en 1921 al frente a la Secretaría de Educación Pública, los resultados de su esfuerzo tardarían algunas décadas en verse. Para 1940, el analfabetismo todavía abarcaba el 52.2\% de la población (LIRA, 2014). Mientras tanto, el privilegio de los libros, periódicos y revistas en donde se volcaban las elucubraciones intelectuales de la época era exclusivo de una mínima fracción de lectores.

Por ello, el impulso nacionalista postrevolucionario tuvo como estrategia un proyecto de Estado que creara, rescatara o re significara imágenes que representaran la identidad mexicana, a partir de la proyección de elementos culturales, políticos y sociales: la relación con la tierra y la valorización del campesino; el diverso patrimonio cultural material e inmaterial, la figura del mestizo aculturado, elementos emblemáticos del catolicismo, la idealización de la cultura indígena, etc.

En el arraigo al pasado histórico, principalmente el de raíz prehispánico y popular, radicó la nueva identidad. Este carácter de novedad consistía en la re significación de los elementos ya existentes elevándolos al rango de patrimonio nacional, no sólo a manera institucional (más bien a través de ella), pero sobre todo en el imaginario común. Yáñez señala cómo "[el Estado] estableció los elementos normativos y técnicos, las instituciones, el marco operativo y las más relevantes acciones para recuperar, concentrar, conservar, proteger, vigilar y difundir los sitios y objetos patrimoniales del pasado histórico del país" (YÁÑEZ, 2006, p.49).

El patrimonio cultural es el 
[...] conjunto de bens, materiais e imateriais, que são considerados de interesse coletivo, suficientemente relevantes para a perpetuação no tempo. O patrimônio faz recordar o passado; é uma manifestação, um testemunho, uma invocação, ou melhor, uma convocação do passado. Tem, portanto, a função de (re)memorar acontecimentos mais importantes; daí a relação com o conceito de memória social. A memória social legitima a identidade de um grupo, recorrendo, para isso, do património (MARTINS, apud RODRIGUES, 2012, p. 4).

Este patrimonio se conforma por expresiones ya "muertas" (vestigios arqueológicos, objetos y símbolos antiguos); pero también -y mucho mejor, para fines prácticos- símbolos, prácticas y tradiciones vivas, tangibles o intangibles que son herederas de un acervo pasado pero que continúan en práctica. La tradición viva es recordatorio actualizado del pasado reivindicado en el presente, el instrumento de la memoria que unifica la comunidad imaginada.

Tampoco es casual que la denominación de patrimonio cultural preste especial atención a los objetos y prácticas pertenecientes a grupos populares: campesinos, indígenas, obreros, etcétera. Su producción cultural es proyectada con valor simbólico agregado al contar con atributos de lo tradicional, no-hegemónico, popular, folclórico, y subraya la intención democrática del proyecto de construcción de identidad nacional, como una deuda vindicadora de la Revolución mexicana (CANCLINI, 1993).

2. Culturas populares en el capitalismo

Características culturales locales y subalternas comenzaron a funcionar como símbolos de la identidad y a formar parte de una tradición colectiva, independientemente del género, estrato social, etnia o entidad. Desde la urbe hasta los espacios rurales, los íconos de la mexicanidad se replicaron. Los bailes y trajes regionales, la comida típica, las artesanías, las canciones populares, etc., se configuraron como productos nacionales que eran difundidos en las películas, el teatro, la pintura, la literatura costumbrista, la música popular en la radio... todo espacio era propicio para la reproducción de imágenes contenedoras de la idealización identitaria. El imaginario fabricó los referentes que integraron disímbolas individualidades en un solo gentilicio, el mexicano.

No obstante, estas muestras de cultura popular que funcionaban como embajadores de la mexicanidad, en la práctica eran minoritarias. Desde la perspectiva de su producción, circulación, consumo y recepción, las prácticas populares suelen encontrarse en desventaja en comparación con otras prácticas culturales hegemónicas y, por ende, están propensas a 
peligrar. García Canclini señala: "Las culturas populares (más que la cultura popular) se configuran por un proceso de apropiación desigual de los bienes económicos y culturales de una nación o etnia por parte de sus sectores subalternos, y por la comprensión, reproducción y transformación, real y simbólica, de las condiciones generales de trabajo y de vida" (CANCLIN, 1989, p.62). Las condiciones materiales de la vida de los grupos populares que las ostentan determinan el curso de su producción cultural, pues lo económico y lo cultural se enlazan de forma indisoluble.

El factor que mayor repercusión tuvo en el devenir de las culturas populares fue la instauración de las políticas de modernización. Entre 1940 y 1970, con la finalización de la Segunda Guerra Mundial como telón de fondo, el país ostentó un crecimiento económico veloz cuando logró posicionarse en el mercado mundial. El llamado "milagro mexicano" estuvo basado en el proteccionismo del Estado y el dinamismo del sector industrial. La política de sustitución de importaciones trajo consigo el estallido de la industria manufacturera que precisó de fuerza obrera para operar. Esta súbita oferta de empleos y subempleos facilitó el flujo migratorio a los espacios urbanos generando un boom poblacional en las metrópolis como Guadalajara, Monterrey y la Ciudad de México (CARTON, 2009). Principalmente esta última, la capital del país, fue a partir de entonces epicentro de las oportunidades económicas.

Sumado al auge de la producción industrial en ciudad, la inversión del sector agrario se redujo notablemente. Como parte del modelo de desarrollo económico, un grupo pequeño de ejidatarios monopolizó el uso de la infraestructura para la producción y comercialización, y contaba con la asistencia técnica para sostener la agricultura comercial. El resto de trabajadores de la tierra laboraba sin infraestructura en tierras de temporal, con producción insuficiente para satisfacer las necesidades de autoconsumo; por lo cual grupos masivos de campesinos se sumaron a la concentración demográfica en la capital con el afán de paliar la desigualdad económica (MÉNDEZ; VIVAR, 2014).

En apenas unas décadas la conformación del país había cambiado radicalmente. Con la creciente centralización poblacional en centros urbanos y la pauperización de la población rural, se creó una brecha generacional entre los practicantes de las culturas populares. Mientras que los jóvenes salen de sus pequeñas poblaciones a procurar oportunidades laborales en la ciudad, aquellos que se han quedado en los pueblos son ancianos. Entre la población joven las prácticas tradicionales pierden vigencia frente a manifestaciones 
culturales extra-regionales por influjo de la modernidad, y el desinterés por la cultura popular encuentra tierra fértil. Al disminuir su capacidad de transmitir de forma continua su memoria tradicional, las prácticas culturales populares devinieron en un fenómeno de dos vertientes: la precarización en el campo de las prácticas culturales debido a la cada vez mayor ausencia de sus detentores y la asimilación cultural a la urbe de las antiguas prácticas tradicionales, resultado natural de la migración.

Este fenómeno ganó la atención de actores societales así como de las instituciones culturales del Estado, que comienzan a emprender acciones de rescate, conservación y difusión cultural. Inclusive, para la década de 1970 el estudio de las culturas populares gana la categoría de campo autónomo en la antropología mexicana. Uno de los pioneros fue Guillermo Bonfil, quien desde sus inicios criticaba el papel centralizador del Estado, que comprende la nación como una cultura unitaria, homogénea y etnocéntrica, y que excluye a los indígenas y a los grupos populares. Para Bonfil era evidente la plurietnicidad y pluriculturalidad del país. Posteriormente figuró como el primer director de la Dirección General de Culturas Populares, institución que actualmente cuenta con dependencias en todos los estados del país, en su afán de descentralizar la gestión cultural (PÉREZ, 2013).

Con este parteaguas comienza a reconocerse la pluralidad y diversidad de la sociedad mexicana. En 1982 se realizó en la Ciudad de México la Conferencia Mundial sobre Políticas Culturales por convocatoria de la UNESCO. De ella surge la "Declaración de México sobre las políticas culturales", en donde se expresan como principios que deben regir las políticas culturales: el reconocimiento de la igualdad y dignidad de todas las culturas; la afirmación de la identidad cultural; el respeto y fomento del pluralismo cultural; y la protección, estímulo y enriquecimiento del patrimonio cultural de cada pueblo, especialmente de las minorías (ORGANIZACIÓN..., 1982).

Para 1988, la Subsecretaría de Cultura da paso al Consejo Nacional para la Cultura y las Artes (Conaculta), atrayendo todas las instituciones y dependencias de carácter cultural. Conaculta se funda bajo la premisa de que el Estado debe promover y difundir el patrimonio y la identidad nacional (Secretaría de Cultura, 2016). En 1989 la Dirección General de Culturas Populares (DGCP), en su búsqueda por generar políticas públicas de la mano de promotores culturales institucionales e independientes, crea como plan de acción el Programa de Apoyo a las Culturas Municipales y Comunitarias (PACMYC). Este programa procura la atención de las demandas en materia de cultura que solicitan las organizaciones populares e indígenas, 
gestionando económicamente sus iniciativas y proyectos. Con esto se fomenta la participación de la sociedad civil en los asuntos culturales.

La formulación de estas políticas culturales que incorporaron mecanismos de participación ciudadana logró el surgimiento de acciones de rescate de manifestaciones artísticas pertenecientes a grupos subalternos, en las que además de los representantes institucionales se sumaron investigadores, agentes culturales, actores de la sociedad civil, grupos populares y entes del ámbito del entretenimiento. Sin embargo, la reivindicación de estas manifestaciones culturales bifurcó tarde o temprano en acciones de corte neo liberal que procuraron el flanco económico en la mercantilización de expresiones de las culturas populares.

3. El caso de los fandangos jarochos

Como se ha mencionado líneas arriba, el proceso migratorio rural-urbano tuvo repercusiones en la realización de algunas prácticas populares. Ejemplo de ello son los fandangos jarochos, fiestas populares del son jarocho (género musical propio del estado de Veracruz) y el zapateado (su danza). Para García de León (2006), los primeros fandangos que podrían ser considerados como propiamente jarochos surgirán desde mediados del siglo XVIII, en una época en donde las regiones del país comenzaban a consolidarse. Pero fue un siglo después, durante la construcción del México independiente, que los fandangos adquirieron una dimensión que esbozaba un aire nacionalista, pues "sirvieron como afirmación de lo propio -lo mestizo o lo criollo-, frente al rechazo de lo extranjero -lo gachupín- [...] La música que se tocaba en aquellas fiestas de principios del siglo XIX [...] sirvió como argumento fuerte a la hora de reconocer "lo mexicano"” (PEREZ, 1994, p. 82). Así, los fandangos, con su música y baile asociados, comenzaban a perfilarse como símbolo identitario para algunas regiones y, por extensión, del país.

Aunque los fandangos continuaron realizándose, aunque precariamente, en comunidades rurales, a finales de 1930 algunos músicos emigraron a las ciudades en busca de trabajo, principalmente a la Ciudad de México, capital del país (FIGUEROA, 2007). Ahí encontraron terreno fértil para practicar el son jarocho y éste ganó simpatía e interés de múltiples investigadores, agentes culturales y entes del ámbito del entretenimiento, por lo que 
el género comenzó a ganar popularidad. No obstante, las demandas del nuevo entorno capitalino propiciaron la alteración de la dinámica del son jarocho hasta ahora concebida para el contexto rural.

Gracias a la expansión urbana, el fandango y su música, el son jarocho, presentaron marcas de hibridación, entendida ésta como un proceso sociocultural "en los que estructuras o prácticas discretas, que existían en forma separada, se combinan para generar nuevas estructuras, objetos y prácticas" (CANCLINI, 2001, p. 14). Esto implica que no es posible entender las culturas como esencial o auténticamente tradicionales, ya que la relación entre lo moderno y lo tradicional está siempre en diálogo, en constante interacción e influencia.

En la migración del espacio rural al urbano, muchos practicantes del son jarocho comenzaron a obedecer las lógicas de la modernidad, lo que generó (y sigue generando) no poca polémica dentro de los círculos musicales tradicionalistas. El son jarocho comenzó a ser pensado a partir de la recepción -y no de la participación, como en el fandango-, y surgió un ente nuevo: el público. A diferencia del fandango, en el que los asistentes son, en su mayoría, participantes (ya sea cantando versos, tocando instrumentos, bailando en la tarima), en el concierto, show, muestra o espectáculo existe una separación entre el espectador y los actores performativos. El espectador accede al bien cultural de forma unidireccional (únicamente a través de la vista y el oído) bajo pago o de forma gratuita, en horarios precisos y calendarizados, en contraste con la espontaneidad del fandango.

La necesidad de percibir una retribución económica alteró la práctica comunitaria del son jarocho en aras de la comercialización. El son como espectáculo comenzó a tener un valor económico que podía ser explotado. Así, los jaraneros alteraron las estructuras de los sones para semejarlos a canciones, mucho más breves y de versos fijos y repetibles, para la comodidad del nuevo público, al que pretendía agradar, pues al situarse en el gusto de la gente se permitió la continuación de la actividad, su fomento y el interés de consumo.

Ejemplo de ello fue Mono Blanco, uno de los grupos de son jarocho pioneros en la Ciudad de México, que abrevaron en la alteración de la práctica del son jarocho pues sus integrantes advertían la necesidad de adaptación del son tradicional a los nuevos espacios de la urbe y los tiempos modernos. Como resultado, la estructura de los sones fue modificada para cuidar "el fluir de la música tomando en cuenta que el oyente no es participante en un fandango sino que se encuentra sentado presenciando un concierto" (FIGUEROA, 2007: 99). 
Otra estrategia para agradar al público fue la fusión del son jarocho con ritmos latinos, música afro, blues y jazz, aceptado la inclusión de nuevos instrumentos y efectos de sonido. Las novedades musicales llegaron de la mano, también, de nuevas letras de canciones. Esta hibridez colocó a estos grupos en el gusto de las masas, especialmente de las generaciones jóvenes, lo que significó una gran venta de discos y mayor reconocimiento del son jarocho dentro y fuera del país.

Sin embargo, el proceso de urbanización del fandango no ha sido lineal ni ha estado exento de debates y reparos. Con ello han surgido, también, una efervescencia por la revalorización de lo tradicional, como iniciativas de enseñanza del son jarocho mediante talleres impartidos por músicos profesionales (es decir, egresados de academias) así como músicos formados por la práctica generacional; la organización de fandangos urbanos abiertos al público, en un esfuerzo por la concientización y revitalización de esta práctica cultural, la invitación a que el espectador se vuelva participante activo.

\section{Fandangos jarochos en el extranjero: el fandango fronterizo}

El son jarocho y el espacio social en el que se practica, es decir, el fandango, es indudablemente una marca identitaria no sólo regional, como también nacional, al fungir como ícono que identifica "lo propio" frente a "lo otro", como se ha expresado anteriormente. Por ello, no resulta extraño que el son y fandango hayan sido usados como seña y bandera de la identidad en el extranjero. Un caso paradigmático es el llamado Fandango Fronterizo, un evento anual que se realiza desde 2007 en la frontera, es decir, en la línea imaginaria que da a bien separar México y Estados Unidos de América mediante una (nada imaginaria) valla metálica. En este fandango, los soneros que habitan en Estados Unidos, sean mexicanos o no, sean jarochos o no, se sitúan alrededor de la tarima del lado americano, mientras que en México, los fandangueros que han llegado desde todas partes del país para este evento, hacen lo propio. Simbólicamente, la comunidad se une a través de la música, a la que no la detienen las fronteras, en cuanto un cantador lanza un verso y en el país vecino un amigo responde; de un lado a otro zapatean los bailarines en pareja o en montón, y las miradas que apenas se divisan de un lado a otro de la malla se multiplican de significado. Los versos entonados así cobran otro cariz más intenso y sentido, y la emoción de encontrar a algún viejo amigo, un familiar o un colega del otro lado coloca en los rostros de asistentes sonrisas y lágrimas. 
El Fandango Fronterizo, además de encuentro lúdico y festivo, representa un acto político que protesta sobre la misma frontera y las políticas de inmigración que separan violentamente a las personas, bajo nociones de territorio y soberanía nacional. Este acto simbólico mediante el cual por unas horas se desdibujan las diferencias de origen, permite pensar en esa otra globalización a la que alude Milton Santos (2000), en donde las fronteras y los nacionalismos no lesionen a los hombres, y el intercambio pacífico entre los pueblos borren poco a poco la belicosidad y competencia que históricamente los ha caracterizado.

El primer fandango de frontera se realizó en 2008 el límite entre Tijuana y San Diego con una iniciativa de un número reducido de soneros que no intuían la dimensión de la convocatoria que generarían. Año con año, cientos de personas continúan reuniéndose en ese punto, en sonora algarabía y regocijo, a pesar de algunos inconvenientes que han tenido con la policía norteamericana. Actualmente, otros Fandangos Fronterizos se han realizado en diversos puntos de México, como Monterrey, Tijuana, San Andrés Tuxtla, Puebla y la Ciudad de México, para visibilizar y sensibilizar sobre la situación de los migrantes que arriesgan la vida en el tránsito hacia Estados Unidos en busca de mejores oportunidades de vida. Uno de ellos, el realizado en 2016 y 2017 en la comunidad La Patrona, Amatlán de los Reyes, Veracruz, se realizó en honor a las Patronas, un grupo de mujeres que habitan en esta localidad, y que desde 1995 alimentan de manera voluntaria a los migrantes que diariamente cruzan sobre el infame tren al sur, "La Bestia", arrojándoles bolsas con comida y agua mientras la máquina sigue en movimiento. En las dos ediciones de Amatlán se realizaron colectas de víveres para apoyar la noble causa de estas mujeres, y en el fandango de 2016 se tocó el son que Patricio Hidalgo compuso para ellas, nombrado Las Patronas.

Estos fandangos de intención social cobran especial sentido en la dinámica de lo local a lo global: es precisamente a partir de las acciones en las regiones que se visibilizan problemáticas que atañen a espacios que las fronteras no limitan. Una dinámica cultural mestiza, híbrida de origen, que se asume como identitaria de una región y un país, alza la voz y permea en la conciencia de individuos más allá de los lindes geográficos artificialmente impuestos.

Esta dinámica de las culturas populares como resultado de la lógica de consumo neoliberal se encuentra actualmente en resistencia, y con devenires particulares que implican conflicto o asimilación, exaltación de lo tradicional (en aras de un esencialismo inexistente) o apertura ante la modernidad, etc. Por otro lado, las culturas populares en México aún son 
utilizadas para la representación de lo nacional, para forjar la identidad de esa comunidad imaginada constreñida por un territorio finito, pero también utilizadas más allá de las fronteras, abiertas a las fluctuaciones del mercado global.

Referencias

ANDERSON, B. Comunidades imaginadas. Reflexiones sobre el origen y la difusión del nacionalismo. México: Fondo de Cultura Económica, 1993.

CANCLINI, N. Las culturas populares en el capitalismo. México: Nueva Imagen, 1989.

CANCLINI, N. Los usos sociales del patrimonio cultural. En FLORESCANO, E. El patrimonio cultural de México. México: Fondo de Cultura Económica, 1993.

CARTON, H. La desagrarización del campo mexicano. Convergencia, v. 16, n. 50. México: Universidad Nacional Autónoma de México, 2009.

FIGUEROA, R. Son Jarocho. Guía histórico-musical. Xalapa: CONACULTA-FONCA, 2007.

LIRA, A. La alfabetización en México: campañas y cartillas, 1921-1944. Traslaciones: revista latinoamericana de lectura y escritura, vol. 1(2). Argentina: Universidad Nacional de Cuyo, 2014.

MÉNDEZ, J.; VIVAR, J. La modernización agrícola en México y sus repercusiones en espacios rurales. Revista Antropologías del Sur, (3). Chile: Universidad Academia de Humanismo Cristiano, 2014.

MOLINA, A. Los grandes problemas nacionales. México: Libro-Mex Ediciones, 1961.

ORGANIZACIÓN DE LAS NACIONES UNIDAS PARA LA EDUCACIÓN, LA CIENCIA Y LA CULTURA. DECLARACIÓN DE MÉXICO SOBRE LAS POLÍTICAS

CULTURALES. Conferencia Mundial sobre Políticas Culturales. 1982. Disponible en: <http://portal.unesco.org/culture/es/files/35197/11919413801mexico_sp.pdf/mexico_sp.pdf> Acceso en 12/05/2017. 
PÉREZ, M. Guillermo Bonfil Batalla. Aportaciones al pensamiento social contemporáneo.

Cuicuilco, vol. 20(57). México: Escuela Nacional de Antropología e Historia, 2013.

PEREZ, R. Estampas de nacionalismo popular mexicano. México: CIESAS, 1994.

RODRIGUES, D. Patrimônio Cultural, Memória Social e Identidade: uma abordagem antropológica. Revista Ubimuseum, n.01. Universidade da Beira Interior (POR), 2012.

VASCONCELOS, J. La raza cósmica. Misión de la raza Iberoamericana. México: EspasaCalpe, 1948.

VIZCAÍNO, F. El nacionalismo mexicano en los tiempos de la globalización y el multiculturalismo. México: Universidad Nacional Autónoma de México, 2004.

VIZCAÍNO, F. Estado multinacional y globalización en México. Sociológica, v. 21, n. 60, 2006. México: Universidad Autónoma Metropolitana.

YÁÑEZ, S. El Instituto Nacional de Antropología e Historia: antecedentes, trayectoria y cambios a partir de la creación del CONACULTA. Cuicuilco, v. 13, n. 38, 2006. México: Escuela Nacional de Antropología e Historia. 